Molecules 2001, 6, 869-874

molecules

ISSN 1420-3049

http://www.mdpi.org

\title{
One-Pot Procedures for Preparing (Dichloroiodo)arenes from Arenes and Diiodine, with Chromium(VI) Oxide as the Oxidant ${ }^{\dagger}$
}

\section{Nicolas Obeid and Lech Skulski*}

Chair and Laboratory of Organic Chemistry, Faculty of Pharmacy, Medical University, Banacha 1, PL 02-097 Warsaw, Poland.

$\dagger$ This paper was presented at the Fifth Electronic Conference on Synthetic Organic Chemistry (ECSOC-5), September 1-30, 2001 (Paper A0006).

* Author to whom correspondence should be addressed; Tel/Fax: +48(22)8226843; e-mail: lskulski@farm.amwaw.edu.pl

Received: 27 September 2001; in revised form 11 October 2001 / Accepted: 12 October 2001 / Published: 31 October 2001

\begin{abstract}
Ten representative (dichloroiodo)arenes, $\mathrm{ArICl}_{2}$, were prepared from the corresponding arenes and diiodine in variable anhydrous mixtures, $\mathrm{ArH} / \mathrm{I}_{2} / \mathrm{CrO}_{3} / \mathrm{AcOH} / \mathrm{Ac}_{2} \mathrm{O} /$ conc. $\mathrm{H}_{2} \mathrm{SO}_{4}$, followed by the addition of conc. hydrochloric acid, used as the source of chlorine; $\mathrm{ArICl}_{2}$ are useful in organic synthesis as mild and selective chlorinating and/or oxidizing agents.
\end{abstract}

Keywords: (dichloroiodo)arenes, arenes, diiodine, chromium(VI) oxide as oxidant

\section{Introduction}

(Dichloroiodo)arenes, $\mathrm{ArICl}_{2}$, have found growing importance in organic synthesis as mild and selective chlorinating and/or oxidizing agents. They offer practical advantages over gaseous $\mathrm{Cl}_{2}$ due to their easy and safe handling. They may also be converted into other important hypervalent iodine reagents, e.g. $\mathrm{ArIF}_{2}, \mathrm{ArIO}, \mathrm{ArIO}_{2}$, $\mathrm{ArI}(\mathrm{OAc})_{2}$, etc. [1] 
$\mathrm{ArICl}_{2}$, yellow crystalline compounds, are light- and heat-sensitive and often unstable to storage. They do not usually give satisfactory microanalyses and their melting/decomposition points are uncertain, depending upon the purity of their freshly prepared batches, the time elapsed since their preparation, and the rate of heating during their melting point estimations [1].

In 1886 Willgerodt [2] developed the most common method up to now for preparing $\mathrm{ArICl}_{2}$, by passing the stream of $\mathrm{Cl}_{2}$ through cooled solutions of ArI in $\mathrm{CHCl}_{3}$. Recently, Japanese chemists [3] repeatedly produced $\mathrm{PhICl}_{2}$ from $\mathrm{PhI}$ (in $94 \%$ crude yield) on a $20 \mathrm{~kg}$ scale using this classic method. Next, they selectively monochlorinated 4-aminoacetophenone with crude $\mathrm{PhICl}_{2}$ on a $24.8 \mathrm{~kg}$ scale, in $87 \%$ yield.

To avoid the hazardous and inconvenient use of gaseous $\mathrm{Cl}_{2}$ to prepare $\mathrm{ArICl}_{2}$ from $\mathrm{ArI}$, a considerable number of various either two-phase $\left(\mathrm{CCl}_{4} /\right.$ conc. aq. $\left.\mathrm{HCl}\right)$ or monophasic liquid-phase methods were reported; the full account of all those methods is given in our latest review [4]. The dichlorine was generated there in situ from conc. hydrochloric acid, used either as a separate phase or as cosolvent, under the action of various oxidants: $2 \mathrm{HCl}+[\mathrm{O}] \rightarrow \mathrm{Cl}_{2}+\mathrm{H}_{2} \mathrm{O}$; mostly, such procedures are easy and relatively safe. However, all former methods [1-4] required the use of iodoarenes, ArI, as the starting substrates which are then chlorinated at their iodine atoms to afford $\mathrm{ArICl}_{2}$. Recently, we presented [5] a novel, one-pot (two-stage) method for preparing eleven $\mathrm{ArICl}_{2}$ from corresponding arenes (ArH) and diiodine used as the starting substrates. ArH were first oxidatively substituted in appropriate anhydrous $\mathrm{I}_{2} / \mathrm{NaIO}_{4}$ or $\mathrm{NaIO}_{3} / \mathrm{AcOH} / \mathrm{Ac}_{2} \mathrm{O} /$ conc. $\mathrm{H}_{2} \mathrm{SO}_{4}$ mixtures with some iodine(III) transient species, $\mathbf{I}^{\mathbf{3 +}}$, to form in situ the organoiodine(III) intermediates, ArISO 4 , viz. $\mathrm{ArH}+\mathbf{I}^{\mathbf{3 +}}+$ $\mathrm{H}_{2} \mathrm{SO}_{4} \rightarrow \mathrm{ArISO}_{4}+3 \mathrm{H}^{+}$. Next, excess conc. (36\%) hydrochloric acid was added to the resulting reaction mixtures, containing the soluble $\mathrm{ArISO}_{4}$ intermediates, to precipitate out the corresponding $\mathrm{ArICl}_{2}$, isolated in 46-88\% crude yields, viz. $\mathrm{ArISO}_{4}$ (not isolated) $+2 \mathrm{HCl} \rightarrow \downarrow \mathrm{ArICl}_{2}+\mathrm{H}_{2} \mathrm{SO}_{4}$. Our environmentally benign method avoided the use of costly iodoarenes, the hazardous application of gaseous $\mathrm{Cl}_{2}$ and chlorinated solvents and, in our opinion, would be particularly suitable for large-scale preparations of $\mathrm{ArICl}_{2}$ from the respective arenes; cf. Ref. [3]. But there are also some inherent limitations in the applicability of this method. Of course, only those isomeric $\mathrm{RC}_{6} \mathrm{H}_{4} \mathrm{ICl}_{2}$ may predominantly be obtained from the monosubstituted benzenes $\mathrm{RC}_{6} \mathrm{H}_{5}$, which are formed in agreement with common orientation rules in the electrophilic substitutions of the used substrates $\mathrm{RC}_{6} \mathrm{H}_{5}$ by said strongly electrophilic $\mathbf{I}^{3+}$ transient species, generated in situ in the anhydrous iodinating reaction mixtures. We have emphasized [5] that further studies are necessary to establish more precisely the limits of the scope of this novel method. Consequently, such novel "model" studies are presented below, but with using chromium(VI) oxide, $\mathbf{C r O}_{3}$, as the oxidant. Hence, it is necessary to recall the results reported in our two former papers [6, 7], where $\mathbf{C r O}_{3}$ was also applied as the effective oxidant.

In 1997 we developed [6] a simple oxidative method for the iodination of various arenes in variable anhydrous $\mathrm{ArH} / \mathrm{I}_{2} / \mathrm{CrO}_{3} / \mathrm{AcOH} / \mathrm{Ac}_{2} \mathrm{O} /$ conc. $\mathrm{H}_{2} \mathrm{SO}_{4}$ systems. For benzene, halobenzenes, and activated arenes, the highest iodination yields were obtained with the following ratio of the reagents: $6 \mathrm{ArH}: 3 \mathrm{I}_{2}: 2 \mathrm{CrO}_{3}$, which favoured the generation of some iodine $(I)$ transient species, $\mathbf{I}^{+}$, acting there as the iodinating agents. In contrast, for deactivated aromatics, the following ratio of the reagents: 
$2 \mathrm{ArH}: \mathrm{I}_{2}: 2 \mathrm{CrO}_{3}$ was applied, which was favourable for generating in the iodinating mixtures some more electrophilic iodine(III) transient species, $\mathbf{I}^{\mathbf{3 +}}$, which reacted with said aromatics to form the soluble organoiodine(III) intermediates, $\mathrm{ArISO}_{4}$ (not isolated); after pouring the resulting reaction mixtures into aqueous $\mathrm{Na}_{2} \mathrm{SO}_{3}$ solutions, the iodoarenes, ArI, were obtained as follows: $\mathrm{ArISO}_{4}+$ $\mathrm{Na}_{2} \mathrm{SO}_{3}+\mathrm{H}_{2} \mathrm{O} \rightarrow \mathrm{ArI}+2 \mathrm{NaHSO}_{4}$. For more details see either our former paper [6], or our latest review [4], pp 1334-1337.

In 1999 we reported [7] a simple method for the conversion of several ArI into corresponding $\mathrm{ArICl}_{2}$. We used excess concd hydrochloric acid oxidised in situ with $\mathrm{CrO}_{3}$ prior dissolved in acetic acid containing also a dissolved (or suspended) ArI. These liquid-phase reactions proceeded according to the following stoichiometry: $3 \mathrm{ArI}+2 \mathrm{CrO}_{3}+12 \mathrm{HCl} \rightarrow \downarrow 3 \mathrm{ArICl}_{2}+2 \mathrm{CrCl}_{3}+6 \mathrm{H}_{2} \mathrm{O}$. For more details see either our former paper [7], or our latest review [4], p 1348.

\section{Results and Discussion}

We now report that by a proper compilation of our three former methods [5-7] it was possible to synthesise, in good or excellent crude yields, ten $\mathrm{ArICl}_{2}$ from corresponding $\mathbf{A r H}$ and diiodine, but with using $\mathrm{CrO}_{3}$ as the effective oxidant. To this end we have worked out three different preparative procedures explained below and detailed in the Experimental:

Two-stage Procedure 1 is applicable for deactivated arenes, e.g. benzoic acid and its methyl and ethyl esters, which are resistant to the action of $\mathrm{CrO}_{3}$ in acidic media. The whole calculated portion of $\mathrm{CrO}_{3}$ was added at the beginning to generate in the reaction mixtures some strongly electrophilic $\mathbf{I}^{3+}$ transient species, which reacted with said $\mathrm{ArH}$ to form the soluble $\mathrm{ArISO}_{4}$ intermediates. Next, they were readily metathesised into insoluble $\mathrm{ArICl}_{2}$, by adding excess concd hydrochloric acid to the resulting reaction mixtures, coloured deep-green due to the presence of $\mathrm{Cr}$ (III) salts. After pouring into ice water, the yellow $\mathrm{ArICl}_{2}$ were isolated by filtration, washed with water and $\mathrm{CCl}_{4}$, and air-dried in the dark.

Three-stage Procedure 2 is applicable for benzene and halobenzenes, which also are fairly resistant towards the action of $\mathrm{CrO}_{3}$ in acidic media. However, higher iodination yields were obtained [6], when these arenes were iodinated in situ with some $\mathbf{I}^{+}$transient species to form corresponding $\operatorname{ArI}$ intermediates (not isolated in this work; cf. Ref. [6]). A second portion of $\mathrm{CrO}_{3}$ had to be added to the resulting reaction mixtures, next followed by excess conc. hydrochloric acid in order to transform the ArI intermediates into $\mathrm{ArICl}_{2}$; cf. Ref. [7] for the explanation and details.

Three-stage Procedure 3 is applicable for such activated arenes as toluene, 1,3-xylene, anisole, and phenetole, which are more or less readily oxidizable [7]. As above, they were at first iodinated with some $\mathbf{I}^{+}$transient species to form the corresponding ArI intermediates (not isolated); next, these intermediates were oxidatively chlorinated in situ, in a manner similar to that described for those in Procedure 2; see Experimental for some preparative differences, also explained in Ref. [7], p 65. 
Thus, in this paper we present a useful modification of our former method [5]. It extends the applicability of the method not only by the use of another oxidant, i.e. $\mathrm{CrO}_{3}$, but also by the development of the one-pot (three-stage) Procedures 2 and 3. Because $\mathrm{CrO}_{3}$ is a stronger oxidant in acidic media than the $\mathrm{NaIO}_{4}$ or $\mathrm{NaIO}_{3}$ previously used $[4,5]$, consequently in the two three-stage Procedures 2 and 3, the total amount of $\mathrm{CrO}_{3}$ was divided into two appropriate parts. Its first portion was added at the beginning of the iodination reactions to form in situ the ArI intermediates (not isolated). Next, the second portion of $\mathrm{CrO}_{3}$ was added, followed by excess conc. hydrochloric acid, which oxidatively chlorinated the ArI intermediates to form the final products, i.e. $\mathrm{ArICl}_{2}$, in the highest yields possible (Table 1).

\section{Experimental}

\section{General}

The starting arenes, ArH, were commercially available products or obtained by reported methods; they were freshly purified prior to use. The reactions were carried out under a fume hood. The toxic residues containing chromium salts were disposed of according to the local safety measures.

The melting points with decomposition (see Table 1) are uncorrected and were measured as follows: after an approximate $\mathrm{mp}$ had been taken in an open capillary tube, a new sample was introduced about $10{ }^{\circ} \mathrm{C}$ below this point, and the temperature was raised at a rate of $10{ }^{\circ} \mathrm{C} \min ^{-1}$. Mps found by us (Table 1) were fairly close to those reported in our former papers [5-9]. Iodometric titrations [2] of the freshly prepared $\mathrm{ArICl}_{2}$ showed that they were of $91-97 \%$ purity.

\section{Procedure 1}

To a stirred and cooled mixture of glacial $\mathrm{AcOH}(10 \mathrm{~mL})$ and $\mathrm{Ac}_{2} \mathrm{O}(5 \mathrm{~mL}), \mathrm{CrO}_{3}(0.63 \mathrm{~g}, 6.3$ mmol) was slowly added portionwise, followed by powdered $\mathrm{I}_{2}(0.8 \mathrm{~g}, 6.3 \mathrm{mmol})$ while keeping the temperature below $30^{\circ} \mathrm{C}$. After one $\mathrm{h}$, a deactivated arene $(11.0 \mathrm{mmol})$ was added, followed by conc. (98\%) $\mathrm{H}_{2} \mathrm{SO}_{4}(1.87 \mathrm{~mL}, 35 \mathrm{mmol})$ added dropwise with stirring, while the temperature was maintained below $25{ }^{\circ} \mathrm{C}$; the stirring was continued for $12 \mathrm{~h}$ at $\mathrm{rt}$, while the reaction mixtures changed colour from dark to deep-green. Conc. (36\%) hydrochloric acid $(15 \mathrm{~mL}$, ca. $490 \mathrm{mmol})$ was slowly added with stirring and cooling; this stirring was continued for 2-3 h, at rt. After pouring into ice water (200 mL), the yellow precipitates were collected by filtration, washed well on the filter with cold water until the washings were colourless and neutral, then with a little $\mathrm{CCl}_{4}$, air-dried in the dark, and weighed. Their mps (with decomp.) were taken without delay, in the manner explained above.

\section{Procedure 2}

To a stirred and cooled solution of $\mathrm{CrO}_{3}(0.66 \mathrm{~g}, 6.6 \mathrm{mmol})$ in a mixture of glacial AcOH $(10 \mathrm{~mL})$ and $\mathrm{Ac}_{2} \mathrm{O}(5 \mathrm{~mL})$, powdered $\mathrm{I}_{2}(2.31 \mathrm{~g}, 18.2 \mathrm{mmol})$ was added portionwise, and this was stirred for a 
further one $\mathrm{h}$. Benzene or a halobenzene $(11.0 \mathrm{mmol})$ was added, followed by conc. $(98 \%) \mathrm{H}_{2} \mathrm{SO}_{4}(0.5$ $\mathrm{mL}, 9.4 \mathrm{mmol}$ ) added dropwise while keeping the temperature below $25{ }^{\circ} \mathrm{C}$. After one $\mathrm{h}$, the second portion of $\mathrm{CrO}_{3}(1.0 \mathrm{~g}, 10 \mathrm{mmol})$ was slowly added portionwise, next followed by conc. (36\%) hydrochloric acid $(15 \mathrm{~mL}$, ca. $490 \mathrm{mmol})$, with cooling below $25^{\circ} \mathrm{C}$; the stirring was continued for an additional one $\mathrm{h}$ at $\mathrm{rt}$. After pouring into ice water $(200 \mathrm{~mL})$, the yellow precipitates collected by filtration were next worked up as those in Procedure 1.

\section{Procedure 3}

To a stirred and cooled solution of $\mathrm{CrO}_{3}(0.66 \mathrm{~g}, 6.6 \mathrm{mmol})$ in a mixture of glacial AcOH $(10 \mathrm{~mL})$ and $\mathrm{Ac}_{2} \mathrm{O}(5 \mathrm{~mL})$, powdered $\mathrm{I}_{2}(2.31 \mathrm{~g}, 18.2 \mathrm{mmol})$ was added portionwise. After the stirring for one $\mathrm{h}$, at $\mathrm{rt}$, an activated arene (11.0 mmol) was added, followed by conc. $(98 \%) \mathrm{H}_{2} \mathrm{SO}_{2}[0.26 \mathrm{~mL}, 4.9 \mathrm{mmol}$ for toluene, or $1.33 \mathrm{~mL}, 25 \mathrm{mmol}$ for 1,3-xylene, anisole, and phenetole] added dropwise with stirring and cooling below $25^{\circ} \mathrm{C}$; the stirring was continued for $60-90 \mathrm{~min}$ at $\mathrm{rt}$, while the iodinating mixtures changed colour to deep-green. Separately, a cooled solution of $\mathrm{CrO}_{3}(1.0 \mathrm{~g}, 10 \mathrm{mmol})$ in water $(5 \mathrm{~mL})$ was diluted with glacial AcOH (15 mL). Next, conc. (36\%) hydrochloric acid (15 mL, ca. $490 \mathrm{mmol})$ was added dropwise with stirring and cooling below $25{ }^{\circ} \mathrm{C}$. To this freshly prepared cold solution, the aforementioned deep-green iodinating mixtures were added immediately, with stirring and cooling; the stirring was continued for an additional one $\mathrm{h}$ at $\mathrm{rt}$. After pouring into ice water $(200 \mathrm{~mL})$, the yellow precipitates collected by filtration were next worked up as those in Procedure 1.

Table 1. Preparative Details, Yields, and Melting Points (with decomposition) of Crude (Dichloroiodo)arenes Prepared from Arenes and Diiodine

\begin{tabular}{|c|c|c|c|c|c|}
\hline Substrate & Product & Procedure & Yield [\%] & $\mathrm{Mp}\left[{ }^{0} \mathrm{C}\right]$ & Lit. $\mathrm{Mp}\left[{ }^{0} \mathrm{C}\right]$ \\
\hline $\mathrm{PhH}$ & $\mathrm{PhICl}_{2}$ & 2 & $94-95$ & $110-112$ & $111-112$ [7] \\
\hline $\mathrm{PhF}$ & $4-\mathrm{FC}_{6} \mathrm{H}_{4} \mathrm{ICl}_{2}$ & 2 & $75-77$ & $104-105.5$ & $106-107$ [7] \\
\hline $\mathrm{PhCl}$ & $4-\mathrm{ClC}_{6} \mathrm{H}_{4} \mathrm{ICl}_{2}$ & 2 & $84.5-85$ & $110-111$ & $110-112[7]$ \\
\hline $\mathrm{PhMe}$ & $4-\mathrm{MeC}_{6} \mathrm{H}_{4} \mathrm{ICl}_{2}$ & 3 & $80-81$ & $97-98$ & $97-98$ \\
\hline PhOMe & 4- $\mathrm{MeOC}_{6} \mathrm{H}_{4} \mathrm{ICl}_{2}$ & 3 & $63-65$ & $75-78$ & $72-73$ \\
\hline $\mathrm{PhOEt}$ & $4-\mathrm{EtOC}_{6} \mathrm{H}_{4} \mathrm{ICl}_{2}$ & 3 & $97-97.5$ & $88-92$ & not given [10] \\
\hline 1,3-Xylene & $2,4-\mathrm{Me}_{2} \mathrm{C}_{6} \mathrm{H}_{3} \mathrm{ICl}_{2}$ & 3 & $75-76.5$ & $95-98.5$ & {$[10]$} \\
\hline $\mathrm{PhCO}_{2} \mathrm{H}$ & $3-\mathrm{HO}_{2} \mathrm{CC}_{6} \mathrm{H}_{4} \mathrm{ICl}_{2}$ & 1 & $75-76.5$ & $185-187$ & $183-185$ [7] \\
\hline $\mathrm{PhCO}_{2} \mathrm{Me}$ & $3-\mathrm{MeO}_{2} \mathrm{CC}_{6} \mathrm{H}_{4} \mathrm{ICl}_{2}$ & 1 & $41-42$ & $108-110$ & $108-110 \quad[7]$ \\
\hline $\mathrm{PhCO}_{2} \mathrm{Et}$ & $3-\mathrm{EtO}_{2} \mathrm{CC}_{6} \mathrm{H}_{4} \mathrm{ICl}_{2}$ & 1 & $69.5-70$ & $99-100$ & $98-100$ \\
\hline
\end{tabular}




\section{References and Notes}

1. (a) Varvoglis, A. The Organic Chemistry of Polycoordinated Iodine. VCH: Weinheim, 1992; (b) Stang, P. J.; Zhdankin, V. V. Chem. Rev. 1996, 96, 1123, (c) Varvoglis, A. Hypervalent Iodine in Organic Synthesis. Academic Press: San Diego, 1997.

2. Willgerodt, C. Die organischen Verbidungen mit mehrwertigem Jod. Enke Verlag: Stuttgart, 1914.

3. Zanka, A.; Takeuchi, H.; Kubota, A. Org. Process Res. Dev. 1998, 2, 270.

4. Skulski L. Organic Iodine(I, III, and V) Chemistry: 10 Years of Development at the Medical University of Warsaw, Poland. Molecules, 2000, 5, 1131-1371; Avail. at URL: http://www.mdpi.org/molecules/papers.51201331.pdf

5. (a) Lulinski, P.; Obeid, N.; Skulski, L., Bull. Chem. Soc. Jpn. in press; (b) Communication at the 3rd Symposium on Iodine Utilization, Nov. 24-25, 2000, Chiba, Japan - see FIU (Forum on Iodine Utilization) Report No. 3, 2000, Chiba, Japan, pp 107-110; (c) see also Ref. [4], pp 1351-1352.

6. Lulinski, P.; Skulski, L. Bull. Chem. Soc. Jpn. 1997, 70, 1665.

7. Kazmierczak, P.; Skulski, L.; Obeid, N. J. Chem. Res., Synop. 1999, 64.

8. Obeid, N.; Skulski, L. Polish J. Chem., 2000, 74, 1609-1615.

9. Krassowska-Swiebocka, B.; Prokopienko, G., Skulski, L. Synlett 1999, 1409.

10. Beringer, F. M.; Gindler, E. M. Iodine Abstr. Rev. 1956, 3, 1; pp 6 and 9.

Sample availability: (Dichloroiodo)arenes are mostly unstable, even when stored in a cooler, therefore samples cannot be supplied on request.

(C) 2001 by MDPI (http://www.mdpi.org). Reproduction is permitted for noncommercial purposes. 